\title{
Visual detection of calcium by GBHA staining in bitter pit affected apples
}

\author{
J. Val*, M.A. Gracia, E. Monge and A. Blanco \\ Estación Experimental de Aula Dei (CSIC). PO Box 202, 50080 Zaragoza, Spain
}

\begin{abstract}
Bitter pit is a physiological disorder of apple fruits apparently caused by a localised calcium deficiency or imbalance in fruits associated with low levels of calcium in the flesh. A new, highly selective method using glyoxal bis(2-hydroxyanil, GBHA) was tested to reveal the presence of calcium within the fruit as a red stain. Water-soluble and insoluble calcium was analysed by capillary electrophoresis and atomic absorption spectroscopy in pitted regions, adjacent sound areas and pulp from sound apples. Both methods, selective calcium staining and mineral analysis, showed that calcium accumulates in the pitted areas of apples affected by bitter pit. However, in mechanically inflicted wounds, the pulp of the apple was heavily stained but not the corresponding fingerprint, indicating a similar mechanism of insoluble calcium accumulation but a different distribution of soluble calcium compared to the pits.
\end{abstract}

Keywords: apple, bitter pit, calcium staining, glyoxal bis(2-hydroxyanil)

\section{INTRODUCTION}

The browning of plant tissues is a manifestation of mechanical damage, certain diseases and physiological disorders, senescence and a hypersensitive reaction induced by pathogenic microorganisms. It is generally believed that the process of browning is due to the loss of cell compartmentalisation and involves the oxidation of polyphenolic compounds by polyphenol oxidase, resulting in the production of polymerised melanin-like pigments (Vaughn and Duke, 1984). Calciumrelated physiological disorders in apples and other fruits also induce corky brown tissues in the fruit pulp. Bitter pit is a physiological disorder of apples (Malus x domestica Borkh) that has been related to calcium deficiency in the fruit (Ferguson and Watkins, 1989). The symptoms generally arise in stored fruit after harvest. Economic losses can be quite substantial since the affected apples cannot be sold as a fresh commodity and must be removed by hand. Many studies have shown that the calcium nutrition of horticultural crops has an important influence on fruit quality (Neilsen and Neilsen, 2003). Indeed, several physiological disorders in the storage organs of fruits and vegetables are related to inadequate calcium supply (Shear, 1975).

The translocation of calcium in higher plants is mainly restricted to xylem sap, following the unidirectional transpiration stream (Kirkby and Pilbeam, 1984), unlike $\mathrm{K}^{+}$and $\mathrm{Mg}^{2+}$ (and $\mathrm{N}$ and P), which are easily transported throughout the phloem (Bergmann, 1992; Tagliavini et al., 2000). Once

\footnotetext{
* To whom correspondence should be sent (e-mail: jval@eead.csic.es).

Received: 4 May 2007; revised 4 July 2007.
} 
incorporated within the leaf, calcium does not recycle, even under conditions of deficiency (Hanger, 1979). Calcium moves into the plant in ionic form or is complexed with malic or citric acids (Bradfield, 1976; Vang-Petersen, 1980). As pointed out by Zocchi and Mignami (1995), calcium is only slightly mobile in the xylem. Thus, it can reach high concentrations in transpiring tissues (leaves) through water mass flow, but is relatively scarce in low transpiring tissues such as fruit, seeds and meristematic tissues supplied via phloem transport.

The existence of calcium gradients throughout the apple has been reported, among others, by Ferguson and Watkins (1989) and Simons and Chu (1980). These authors showed that the level of Ca is highest in the skin and core and lowest in the outer cortex. In the longitudinal axis, the Ca level is lower at the calyx end of the fruit than in the part near to the stem. However, little is known about the distribution of calcium throughout apples affected by bitter pit. In this paper, we propose a new method that uses glyoxal bis 2-hydroxyanil (GBHA) to visually detect calcium in plant tissues. GBHA is a highly specific $\mathrm{Ca}^{2+}$ reagent widely used to determine calcium concentrations in water, milk and soil (Merck, 2003a,b,c). It was first used for the cytochemical identification of calcium by Kashiwa and Atkinson (1963) and later evaluated for calcium staining in pancreatic islets (Wolters et al., 1979). It has also been used to study the acute effects of glucose on mobile Ca (Wolters et al., 1980), and the histochemical determination of calcium in the salivary glands of cats (Harrison et al., 1993). Although GBHA is used for various analytical or histological purposes, it has never been applied to analyse calcium allocation in fruit sections.

We estimated calcium accumulation using the GBHA-technique in three types of apple tissue: bitter pit spots, sound areas adjacent to the pits, and pulp from sound apples. Other tissue from mechanically injured apples was also analysed. The different staining patterns were then compared with the corresponding data on water-soluble and insoluble calcium provided by capillary electrophoresis and atomic absorption spectroscopy. The aim of this paper is to introduce the calcium staining GBHA-technique as a tool for studying calcium distribution in apples affected by calciumrelated physiopathologies.

\section{MATERIALS AND METHODS}

\section{Plant material}

Samples were taken from apple cv. Smoothee Golden Delicious, grafted on M9, from a commercial orchard of the ALM (Angel Luengo Martínez) Group located in the township of Quinto de Ebro (Zaragoza, Spain). Sound and bitter pit affected apples were sampled after two months of normal cold storage.

\section{Methods}

Staining of fruit sections for calcium 
Fruit sections were stained with a solution containing $0.2 \%(\mathrm{w} / \mathrm{v})$ glyoxal bis(2-hydroxyanil) (GBHA), 1 \% (w/v) NaOH, 45 \% (v/v) absolute ethanol and $45 \%$ (v/v) chloroform. Transversal or longitudinal $0.5 \mathrm{~cm}$ sections following the equator or the vertical axis were carefully cut with a meat slicer to obtain a flat surface. An aliquot of the dying solution was sprayed with a Pasteur pipette over a calcium-free filter paper after a blank assay. Slices were pressed down for 10 seconds against the moistened paper and the final image was obtained after the paper had dried (approximately $10 \mathrm{~min}$ ), where red areas indicated the presence of calcium.

\section{Selectivity and interferences of GBHA staining}

To verify whether GBHA stained other elements besides calcium, one strip of filter paper was assayed per solution. The strips were placed in the solutions listed in Table $1\left(\mathrm{~K}^{+}, \mathrm{Sr}^{2+}, \mathrm{Ba}^{2+}, \mathrm{NH}_{4}^{+}\right.$, $\mathrm{Fe}^{3+}, \mathrm{Fe}^{2+}, \mathrm{Mn}^{2+}, \mathrm{Cu}^{2+}, \mathrm{Zn}^{2+}, \mathrm{Na}^{+}, \mathrm{Mg}^{2+}$, Citrate, Oxalate, Malate, Nitrate, Chloride, Ascorbate, Phosphate, Sulphate, Carbonate, Sucrose, Fructose and bovine serum albumin).

The counter-ion for all cations assayed was $\mathrm{Cl}^{-}$and for anions $\mathrm{K}^{+}$. Those solutions containing cations were $1000 \mu \mathrm{g} / \mathrm{mL}$, while anions and other species were $10000 \mu \mathrm{g} / \mathrm{mL}$. After drying for $10 \mathrm{~min}$, a drop of $0.2 \%$ GBHA solution was placed on the surface of the strip.

To verify whether other elements might mask the $\mathrm{Ca}^{2+}$-GBHA reaction, strips of filter paper were placed in a solution containing $5 \mathrm{mg} / \mathrm{L} \mathrm{Ca}^{2+}$ and dried for $10 \mathrm{~min}$, after which a drop of solution containing 1000 or $10000 \mathrm{mg} / \mathrm{L}$ of a given species was applied. If an inhibition of the red colour development was detected, lower concentrations were assayed until the interference disappeared. All the assays were repeated ten times.

\section{Induction of mechanical injuries to the fruit}

As an alternative method to induce localized brown areas in the apple pulp, we applied mechanical blows to the surface of the fruit which resulted, with time, in local degradation of the tissue combined with intra-cell desiccation and browning of phenolic compounds released by disrupted cells. In brief, an aluminium rod (1 cm diameter, $340 \mathrm{~g}$ ) with a rounded tip was dropped onto the equator of the apple surface from a height of $10 \mathrm{~cm}$. Four equidistant blows per apple were administered on the equatorial line. The area of impact was marked and samples were sliced to obtain a section including the middle point of the impact. Samples were stained after 2, 6 and 12 days of the injury.

\section{Isolation and extraction of tissue}

Bitter pit affected apples were distributed in four replicates containing 20 pieces of fruit each. Ten pieces of fruit were sliced for staining, and the other ten were used to remove affected and sound tissues (surgically removed). Material extirpated from the ten apples was mixed and $2 \mathrm{~g}$ of the bulk was taken to be homogenized using a mortar and pestle with $10 \mathrm{~mL}$ of Milli-Q quality water and 
centrifuged at $2000 \mathrm{~g}$ for $10 \mathrm{~min}$. After vacuum filtration through $0.22 \mu \mathrm{m}$, calcium concentrations in the supernatants were analysed by capillary electrophoresis.

The pellets were dried and later wet-digested in $\mathrm{HNO}_{3} / \mathrm{H}_{2} \mathrm{O}_{2}$ in accordance with Pequerul et al. (1993). Calcium in the water-insoluble residues was determined by atomic absorption spectroscopy.

The same procedure was applied to analyse soluble and insoluble calcium from mechanically wounded tissues and the apparently sound pulp adjacent to them.

\section{Calcium analysis by capillary electrophoresis}

Analyses were carried out on a Beckman 'P/ACE MDQ' with the working electrolyte $16 \mathrm{mM}$ 4-Aminopiridine $\mathrm{pH}=7.3$ and $4 \mathrm{mM}$ of ether 18-Crown-6. The voltage used for separation was $30 \mathrm{~kW}$ and the detection wavelength was $214 \mathrm{~nm}$. Each run took about $5 \mathrm{~min}$.

\section{Statistics}

As described above, all analytical data are the mean of four replications, each containing material from ten pieces of fruit. In Table 2, standard deviations are given for each value. No analysis of variance was needed as results were consistent.

\section{RESULTS AND DISCUSSION}

To our knowledge, there is no simple, rapid method available on the market (or cited in the literature) for detecting calcium and its distribution within fruit. Other authors have used GBHA at high concentrations for histochemical purposes (3.3 \% Harrison et al., 1993; or 5\% Wolters et al., 1979, 1980) with $75 \%$ ethanol and $3.4 \% \mathrm{NaOH}$. We assayed these procedures with freshly cut apples, but obtained a dark and uniform red stain over the whole slice, which did not show variations. After washing with water and ethanol some details were revealed, but still a dark tint coloured the background, making this method unsuitable for distinguishing differences between areas of the fruit with different calcium concentration. Furthermore, with the original methods no fingerprint in filter paper could be obtained. After an optimization process which included changes in the organic solvents and in the adequate concentration of GBHA for staining flat fruit sections, we developed another staining solution, including chloroform, which allows paper fingerprints to be obtained and uses a lower GBHA concentration ( $0.2 \%)$ as a compromise between a clear background and a neat stain of calcium accumulation in specific areas. The same procedure may be used to study alterations in the dynamics and distribution of calcium in other fruits and plant organs. The technique has been successfully applied to pears, mandarins, and tomato fruit before maturity and stems from apple and tomato (data not shown).

It was not possible to establish a quantitative relationship between the real calcium concentration in the fruit tissue and the intensity of red colour after GBHA staining either in the fruit surface or in the paper fingerprint. However, for semi-quantitative purposes, the visually estimated 
intensity of the red colour of the stained fingerprint from bitter pit tissues containing calcium concentrations around $12 \mathrm{mg} / 100 \mathrm{~g}$ in a fresh matter basis is similar to the red colour obtained when the filter paper is dipped in standard calcium solutions containing 100-200 mg/L and afterward stained with GBHA. Likewise, the fingerprint stain of sound apple containing 2-5 mg Ca/100 g (fresh matter) is similar to the colour of a stained paper strip submerged in a $20-50 \mathrm{mg} / \mathrm{L}$ Ca solution. Lower concentrations of calcium cannot be distinguished.

In order to test the potential interference of other ions frequently present in apple samples, a systematic study was carried out to determine calcium in their presence. First, we verified whether GBHA stained other elements besides calcium under our working conditions. Then we analysed whether any of these compounds masks the reaction of GBHA with calcium. None of the compounds assayed (listed in Table 1) developed a red colour in response to GBHA, indicating that the reaction is highly selective for calcium ions and that the presence of other species generally does not produce a red stain (Table 1, column '-Ca'). The formation of the $\mathrm{Ca}^{2+}$-GBHA complex was only inhibited by concentrations of magnesium above $400 \mu \mathrm{g} / \mathrm{mL}$ and sodium above $200 \mu \mathrm{g} / \mathrm{mL}$ (Table 1, column ' + Ca'). In fact, it is very unlikely that other possible cationic interferences apart from $\mathrm{K}, \mathrm{N}$ and $\mathrm{P}$ can occur in fruit tissue as these are the major mineral components of the apple, while $\mathrm{Ca}$ and $\mathrm{Mg}$ are present in lower concentrations in the fruit flesh. Other elements such as $\mathrm{Fe}, \mathrm{Mn}, \mathrm{Cu}, \mathrm{B}$ and $\mathrm{Zn}$ appear at the trace level (Noe et al., 1997).

According to the results from the apple sections and their paper fingerprints after staining with GBHA, calcium accumulates in the bitter pit spots, as reported by Faust and Shear (1969) and Perring (1986). There was an intense red on the area corresponding to the pits, while the surrounding areas were light red, indicating lower calcium content. On the fruit surface, only the pits had an intense red stain (Figure 1.1).

In sound apples the pattern was different, with a uniform superficial calcium distribution on the filter paper. However, the surface of the fruit section was only slightly stained. Further analysis of the data in Figure 1.1, suggests that the pits can attract and accumulate calcium from their surroundings.

According to Steenkam et al. (1983) most of the calcium in apples in terms of concentration (mg/100 g dry matter) is insoluble in sound and pitted tissue (57.9 \% and $69.7 \%$, respectively). However, according to our chemical analyses, while both sound and pitted tissue from the bitter pit affected fruit had more insoluble calcium, soluble and insoluble forms were at similar concentrations in sound apples (Table 2). On the other hand, the water-soluble calcium concentration was not substantially different among the three tissues.

As seen in Table 2, on the basis of fresh matter (FM), the level of calcium in the pits (12.71 $\mathrm{mg} / 100 \mathrm{~g} \mathrm{FM}$ ) was at least three times higher than in adjacent and sound tissues (4.13 and $3.25 \mathrm{mg} / 100$ g FM, respectively). However, the water-soluble calcium concentration was similar in all three tissues, while the insoluble fraction was four times higher in the pits than in the adjacent sound pulp and seven 
times higher than in the pulp of a sound apple. Therefore, comparing the data in Table 2 with Figure 1.1, it appears that the fingerprint of the calcium-GBHA complex on the filter paper does not quantitatively measure the soluble fraction in the apple. The strength of the staining does not correspond with the actual soluble calcium concentration of the pits. In addition, with respect to the direct stain of the pulp, although the pits were more coloured, the tonality of the adjacent sound tissue was more tenuous than the flesh of the sound apple. In fact, GBHA staining of sound apples provides a more intense coloration than affected apples, excluding the pit area.

On the surface of the fruit, only the pitted areas stained red, suggesting that they contain some insoluble calcium complex that does not appear or is only present in minor quantities in the rest of the fruit cells. This form of calcium is highly visible in pit cells, where it may be located in the apoplast (i.e., cell walls and intracellular spaces), as suggested by a series of histological experiments using GBHA on fresh sections of apple shown in Figures 1.2 and 1.3. As seen in Figure 1.2, the pit was stained a deep red while the rest of the tissue had lighter red coloration. Figure 1.3 details how the strength of GBHA dyeing was much lower in sound tissue (A) than in the pits (B).

Marschner (1986) suggested that during fruit ripening, $\mathrm{Ca}^{2+}$ is solubilised from its binding sites and is redistributed inside the cells, probably accumulating in the vacuole. Thus, the free calcium inside the vacuole would be water-soluble and more abundant in bitter pit affected tissue than in sound tissue. However, our analyses of the three types of apple fruit tissue demonstrate the opposite. In the sound area of sound and bitter pit affected fruit, the fraction of soluble calcium accounted for 37-51 \% of the total calcium content. In the pitted area the fraction decreased to $14 \%$, despite having the highest absolute value of all three tissues (Table 2). Probably, the high level of calcium in the pits is in the apoplastic compartment, as suggested in Figures. 1.2 and 1.3.

After establishing that calcium accumulates in the spots of bitter pit affected apples, we analysed whether calcium moved to these areas before or after damage. Several hundred sections of apples without symptoms but with a high risk of bitter pit were assayed for a Ca-stain. The risk of bitter pit was deduced from the fact that the fruit selected for this experiment was taken from particular lines with an incidence of the disorder higher than $65 \%$. Within this kind of fruit, there was no special distribution of calcium before visual symptoms appeared, and a high percentage did indeed develop bitter pit after several days at room temperature.

On the whole, necrotic areas in the fruit generally accumulated calcium irrespective of their origin (manipulation, pest, damage), as revealed by GBHA staining (data not shown). A simple experiment was designed to elucidate the pattern of calcium accumulation in damaged areas using mechanically inflicted wounds.

As shown in Figure 1.4, after mechanical injury the wounded area of the pulp was heavily stained but not the corresponding fingerprint, even 2-12 days after impact. Chemical analysis of wounded tissues 2, 6 and 12 days after impact showed an increase with time in insoluble calcium accumulation, while the water-soluble fraction remained almost unaltered (Table 2). However, in 
bitter pit affected apples, both the pits in the pulp and the paper fingerprints were heavily stained. This suggests that calcium moves into specific areas after damage, and although the cellular mechanism in response to mechanical injury may be similar to bitter pit in terms of the accumulation of insoluble calcium, it differs in the calcium susceptible to reaction with GBHA in the paper.

\section{CONCLUSIONS}

The highly selective GBHA-based method was used to reveal the presence of calcium in apple sections. The reaction was only inhibited by high sodium or magnesium concentrations. The results with bitter pit affected apples indicate that pitted areas accumulate calcium, which reacts with GBHA on the surface of the filter paper and in the pulp of the fruit. The highest level of insoluble calcium was found in the pits.

Before pits appear, the staining of slices from apples predisposed to bitter pit did not reveal any special pattern of calcium distribution in the cortex.

Following mechanical injuries, wounded areas of healthy apples only accumulated insoluble calcium, which was detected $48 \mathrm{~h}$ after impact.

After more than a century of research, we still do not fully understand the details behind the development of bitter pit. The proposed method could be useful for studying this physiopathology in more detail, as well as other disorders related to calcium distribution in plant organs.

\section{ACKNOWLEDGEMENTS}

The authors thank the ALM Group for the facilities provided. This work was supported by research grants AGL2004-04305/AGR (Plan Nacional de Recursos y Tecnologías Agroalimentarias) and PM017/2004 (Gobierno de Aragón).

\section{REFERENCES}

Bergmann W. (1992). Nutritional disorders of plants: development, visual and analytical diagnosis. Stuttgart, Germany: Gustav Fischer Verlag.

Bradfield E.G. (1976). Calcium complexes in the xylem sap of apple shoots. Plant and Soil 44: 495499.

Faust M. and Shear C. B. (1969). Biochemical changes during the development of cork spot of apples. Plant Foods for Human Nutrition 19: 255-265.

Ferguson I. B. and Watkins C.B. (1989). Bitter pit in apple fruit. Horticultural Reviews 11: 289-355.

Hanger B.C. and Shear C.B. (1979). The movement of calcium in plants. Communications in Soil Science and Plant Analysis 10: 171-193.

Harrison J. D., Triantafyllou A., Baldwin D., Garret J. R. and Schäfer H. (1993). Histochemical and biochemical determination of calcium in salivary glands of cats. Histochemistry 100, 155-159.

Kashiwa H.K. and Atkinson W.B. (1963). The applicability of a new Schiff base, glyoxal bis (2hydroxyanil), for the cytochemical localization of ionic calcium. Journal of Histochemistry and Cytochemistry 11: 258-264. 
Kirkby E. A. and Pilbeam D. J. (1984). Calcium as a plant nutrient. Plant, Cell and Environment 7: 397-405.

Marschner H. (1986). Mineral nutrition of higher plants. London, UK: Academic Press.

Merck (2003a). Calcium in soil. Available at http://pb.merck.de/servlet/PB/menu/1170420/1170420.html . Consulted 10 June 2008.

Merck (2003b). Calcium in milk. http://pb.merck.de/servlet/PB/menu/1169350/1169350.html . Consulted Consulted 10 June 2008.

Merck (2003c). Calcium in water. http://pb.merck.de/servlet/PB/menu/1168980/1168980.html. Consulted Consulted 10 June 2008.

Neilsen G.H. and Neilsen D. (2003). Nutritional requirements of apple. In: D.C. Ferree and I.J. Warrington (eds), Apples: Botany, Production and Uses. Wallington: CABI Publishing. pp. 267-302.

Noé N., Eccher T., Porro D. and Stainer R. (1997) Quality of Golden Delicious apples as affected by season and by nitrogen and potassium mineral nutrition. Acta Horticulturae 448: 487-497.

Pequerul A., Perez C., Madero P., Val J. and Monge E. (1993). A rapid wet digestion method for plant analysis. In: M.A.C. Fragoso and M.L.V. Beusichem (eds), Optimization of Plant Nutrition Dordrecht: Kluwer Academic Publishers, pp. 3-6.

Perring M.A. (1986). Incidence of bitter pit in relation to the calcium content of apples: Problems and paradoxes, a review. Journal of the Science of Food and Agriculture 37: 591-606.

Shear C. B. (1975). Calcium-related disorders of fruits and vegetables. HortScience 10: 361-365.

Simons R.K. and Chu M.C. (1980). Scanning electron microscopy and electron microprobe studies of bitter pit in apples. Acta Horticulturae 92 : 57-70.

Steenkam J., Terblanche J.H. and de Villiers O.T. (1983). The role of organic acids and nutrient elements in relation to bitter pit in Golden Delicious apples. Acta Horticulturae 138: 35-42.

Tagliavini M., Zavalloni C., Rombola A. D., Quartieri M., Malaguti D., Mazzanti F., Millard P. and Marangoni B. (2000). Mineral nutrient partitioning to fruits of deciduous trees. Acta Horticulturae 512: $131-140$.

Vang Petersen O. (1980). Calcium nutrition of apple trees: a review. Scientia Horticulturae 12: 1-9. Vaughn K.C. and Duke S.O. (1984) Function of polyphenol oxidase in higher plants. Physiologia Plantarum 60: 106-112.

Wolters G.H.J., Pasma A., Konijnendijk W. and Bouman P.R. (1979). Evaluation of the glyoxal-bis(2-hydroxyanil)-method for staining of calcium in model gelatin films and pancreatic islets.

Histochemistry 62: 137-151.

Wolters G.H.J., Pasma A., Konijnendijk W. and Bouman P.R. (1980). Effects of calcium manipulation and glucose stimulation on a histochemically detectable mobile calcium fraction in isolated rat pancreatic islets. Histochemistry 66: 125-135.

Zocchi G. and Mignani I. (1995). Calcium physiology and metabolism in fruit trees. Acta Horticulturae 383: 15-23. 
Table 1. Study of cationic, anionic and other possible interferences in the determination of calcium by the GBHA method.

\begin{tabular}{|c|c|c|c|}
\hline & \multicolumn{2}{|c|}{ Red colour development } & \multirow{2}{*}{ Interference } \\
\hline & - Ca & $+\mathrm{Ca}$ & \\
\hline \multicolumn{4}{|l|}{ Cations $(1000 \mu \mathrm{g} / \mathrm{mL})$} \\
\hline $\mathrm{K}^{+}, \mathrm{Sr}^{2+}, \mathrm{Ba}^{2+}, \mathrm{NH}_{4}^{+}, \mathrm{Fe}^{3+}, \mathrm{Fe}^{2+}, \mathrm{Mn}^{2+}, \mathrm{Cu}^{2+}, \mathrm{Zn}^{2+}$ & - & + & \\
\hline $\mathrm{Mg}^{2+}$ & - & - & $>400 \mu g \mathrm{Mg} / \mathrm{mL}$ \\
\hline $\mathrm{Na}^{+}$ & - & - & $>200 \mu \mathrm{g} \mathrm{Na} / \mathrm{mL}$ \\
\hline \multicolumn{4}{|l|}{ Anions $\left(10000 \mu \mathrm{g} / \mathrm{mL}^{-}\right)$} \\
\hline $\begin{array}{l}\text { Citrate, Oxalate, Malate, Nitrate, Chloride, Ascorbate, } \\
\text { Phosphate, Sulphate, Carbonate }\end{array}$ & - & + & \\
\hline \multicolumn{4}{|l|}{ Others $(10000 \mu \mathrm{g} / \mathrm{mL})$} \\
\hline Sucrose, Fructose, Bovine serum albumin & - & + & \\
\hline
\end{tabular}

Table 2. Water soluble and insoluble calcium concentrations in the fruit mesocarp of bitter pit affected and sound apples.

\begin{tabular}{lcc}
\hline & \multicolumn{2}{c}{ Calcium (mean $\pm \mathrm{SD}, \mathrm{mg} / \mathrm{100} \mathrm{g}$ fresh matter) } \\
\cline { 2 - 3 } Fruit part & Water-soluble & Insoluble \\
\hline Pits & $1.80 \pm 0.18$ & $10.91 \pm 1.20$ \\
Adjacent to pits & $1.51 \pm 0.55$ & $2.62 \pm 0.57$ \\
Sound apple & $1.65 \pm 0.24$ & $1.60 \pm 0.10$ \\
Wounded tissue & & \\
2 days & & $2.61 \pm 0.43$ \\
6 days & $1.36 \pm 0.16$ & $1.92 \pm 0.41$ \\
12 days & $1.60 \pm 0.11$ & $6.27 \pm 0.43$ \\
\hline
\end{tabular}




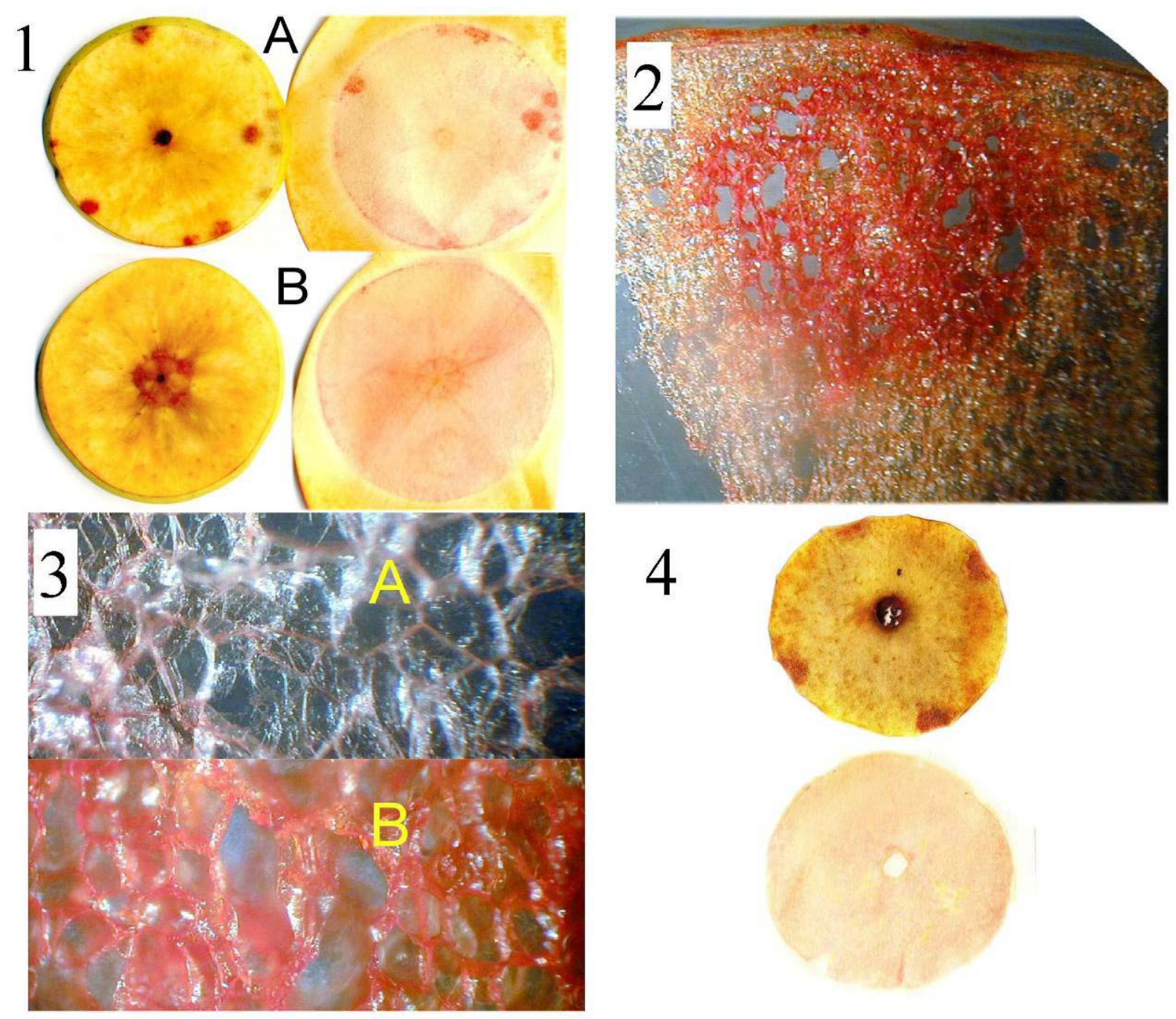

Figure 1. (1) Fruit slices (left) and the corresponding fingerprints on the filter paper (right) after GBHA staining of: (A) bitter pit affected apple fruit, (B) sound apple. (2) GBHA calcium staining of a thin section of apple. The red area corresponds to a pitted zone. (3) Magnification of sound (A) and bitter pit (B) apple tissues following GBHA staining. (4) GBHA stain of a fruit slice from a mechanically injured apple six days after impact (upper), and the corresponding paper fingerprint (lower). 